\section{ECCOMAS}

Proceedia

\author{
COMPDYN 2021 \\ $8^{\text {th }}$ ECCOMAS Thematic Conference on \\ Computational Methods in Structural Dynamics and Earthquake Engineering \\ M. Papadrakakis, M. Fragiadakis (eds.) \\ Streamed from Athens, Greece, 28 - 30 June 2021
}

\title{
VIBRATION CONTROL OF WIND TURBINE TOWERS WITH KDAMPER-BASED DESIGNS
}

\author{
Konstantinos A. Kapasakalis ${ }^{1}$, Ioannis A. Antoniadis ${ }^{2}$, and Evangelos J. Sapountzakis ${ }^{1}$ \\ ${ }^{1}$ Institute of Structural Analysis and Antiseismic Research, School of Civil Engineering, \\ National Technical University of Athens, Zografou Campus, GR-157 80 Athens, Greece \\ e-mail: kapasakalis@mail.ntua.gr,cvsapoun@cental.ntua.gr \\ ${ }^{2}$ Dynamics and Structures Laboratory, School of Mechanical Engineering, \\ National Technical University of Athens, Zografou Campus, GR-157 80 Athens, Greece \\ e-mail: antogian@central.ntua.gr
}

\begin{abstract}
The application of dynamic vibration absorbers (DVA) to Wind Turbine (WT) towers has the potential to significantly improve the damping of the tower and the nacelle dynamic responses, thus increasing the reliability of WTs. The Tuned Mass Damper (TMD) is considered a benchmark for vibration absorption of WT. However, its effectiveness is limited by the requirement of large masses, in association to its installation location. Thus, an alternative concept is introduced, which is based on a novel passive vibration absorption configuration, the extended KDamper concept. The KDamper is essentially an extension of the conventional $T M D$, introducing appropriate negative stiffness (NS) elements. Instead of increasing the additional mass, the vibration absorption capability of the KDamper can be increased by increasing the value of the NS element. Therefore, the KDamper always indicates better isolation properties than a TMD with the same additional mass. In this paper, the performance of these concepts is examined for increasing the damping of WT towers. A constrained optimization procedure is presented, from which the optimal design parameters are obtained. Although both concepts present a good behavior, the KDamper-based design significantly increases the effective damping of the WT tower, retaining the additional masses in reasonable ranges.
\end{abstract}

Keywords: Wind Turbines, KDamper, Negative Stiffness, Vibration Control, Damping, Tuned Mass Damped. 


\section{INTRODUCTION}

Wind power continues its rapid growth worldwide and as a result, wind farms are likely to comprise a significant portion of the total production of wind energy. The high-quality wind resource and the proximity to load centres make wind energy a compelling proposition. The WWEA predicts that offshore wind farms of $150 \mathrm{GW}$ will operate in the EU by 2030, contributing $14 \%$ of the EU's total electricity consumption. However, the above prediction is very ambitious. In recent years, several failures have been recorded in existing wind turbines (WT). It is estimated that the structural failure (tower, foundation) of the installed WT amounts up to $10 \%$ [1]. In addition, the structural and foundation costs are excessively high, reaching up to $17 \%$ for land based (onshore) and fixed bottom offshore WT.

From the above comments, and according to the International Energy Agency [2], it emerges as top priority to enhance research to avoid WT structural failures. A way to extend the feasibility of Wind Turbine towers is by means of structural control.

The concept of a resonant damper, like a Tuned Mass Damper (TMD) is among the approaches that have received the most attention in the literature. The principal of the TMD system [3] is the degradation of the dynamic response of the system through energy transfer to a system of an additional mass, designed with optimum characteristics and adapted in a suitable position in the structure [4,5]. Active [6,7] and semi-active [8-12] TMD have been examined thoroughly in the latest year, enhancing the damping performance of the passive TMD. The downside of such designs is that their performance is directly (or obliquely) depended by the accuracy of the actuators output, which over time can have an alternation in its performance. In addition, the essential limitations of all the aforementioned TMD-related concepts, are related with the location and the selected mass of these devices. TMD should be installed at the top of the tower or inside the nacelle in order to be effective, and is associated with large additional masses, which constitutes a major limitation, since additional mass is highly undesirable at the top of the WT. In addition, a slight alteration in the system parameters can alter the TMD tuning and reduce the system performance [13].

In this paper, the (extended) KDamper is intervened between the nacelle and the WT tower. The KDamper, introduced in [14], is essentially an extension of the TMD, by incorporating appropriate negative stiffness (NS) elements. Instead of increasing the additional mass, the vibration isolation capability of the KDamper can be increased by the NS, overcoming the sensitivity problems of TMDs as the tuning is mainly controlled by the NS. Thus, the KDamper always indicates better isolation properties than a TMD with the same mass, finding numerous applications for vibration absorption in structural systems [15-24]. Although the KDamper incorporates a NS element, it is designed to be statically and dynamically stable.

Section 2 of the paper presents the dynamic model of the WT tower. The developed model is an assemblage of prismatic beam elements with sway DoFs considered to be the dynamic ones. In order to verify the validity and the efficiency of the developed model, a set of simplified analyses were conducted and compared with a commercial software package based on FEM. The aerodynamic load is taken into account by generating artificial basic wind velocities following the corresponding regulations of EC1 and applying it at the WT following the procedure described in [25]. Section 3, presents the optimization procedure for the EKD. The independent design variables are presented, and proper limitations and constraints are imposed on the design variables and the system main dynamic responses, based on the proposed constrained engineering-criteria driven optimization procedure. In section 4, the numerical results are presented, where the effectiveness of the EKD is verified. A comparison with a conventional TMD ( $2 \%$ mass) confirms that the EKD manages to significantly increase the effective damping of the WT tower, and thus mitigate the WT dynamic responses, with small 
additional masses and a realistically designed configuration. In section 5 , the conclusive remarks are presented, based on the nonlinear dynamic responses of the controlled WT tower with the proposed VCS and the comparison with the conventional TMD.

\section{MATHEMATICAL MODELLING OF WIND TURBINE FOUNDED ON MONOPILE FOUNDATION}

\subsection{Dynamic Model of WT with Monopile Foundation}

An onshore wind turbine (WT) tower of length $l_{t}$ and variable tubular cross-section $A_{t}(x)$ is examined, as presented in Figure 1. The tower supports the NREL baseline 5MW nacelle and rotor $[26,27]$. In order to account the inertial forces applied by the mechanical parts (nacelle, rotor, and blades) an additional concentrated mass $m_{\text {top }}$ is added at the top of the tower [27]. The WT is founded on a monopile of length $l_{p}$ of cylindrical cross-section $A_{p}$. The monopile is embedded in a layered Winkler type soil profile represented by a Kelvin-Voigt element (i.e. elastic spring - dashpot parallel configuration $k_{s}-c$ ).

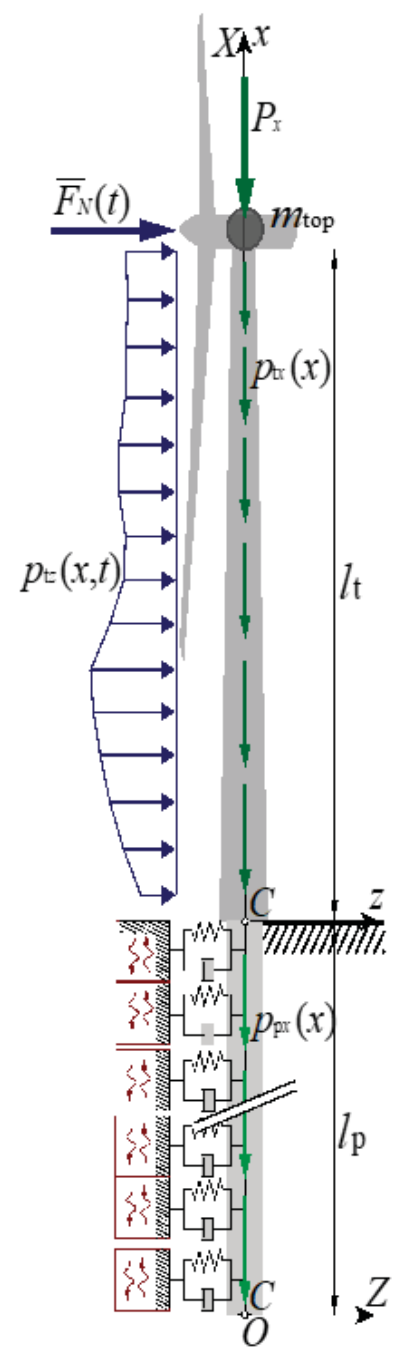

(a)

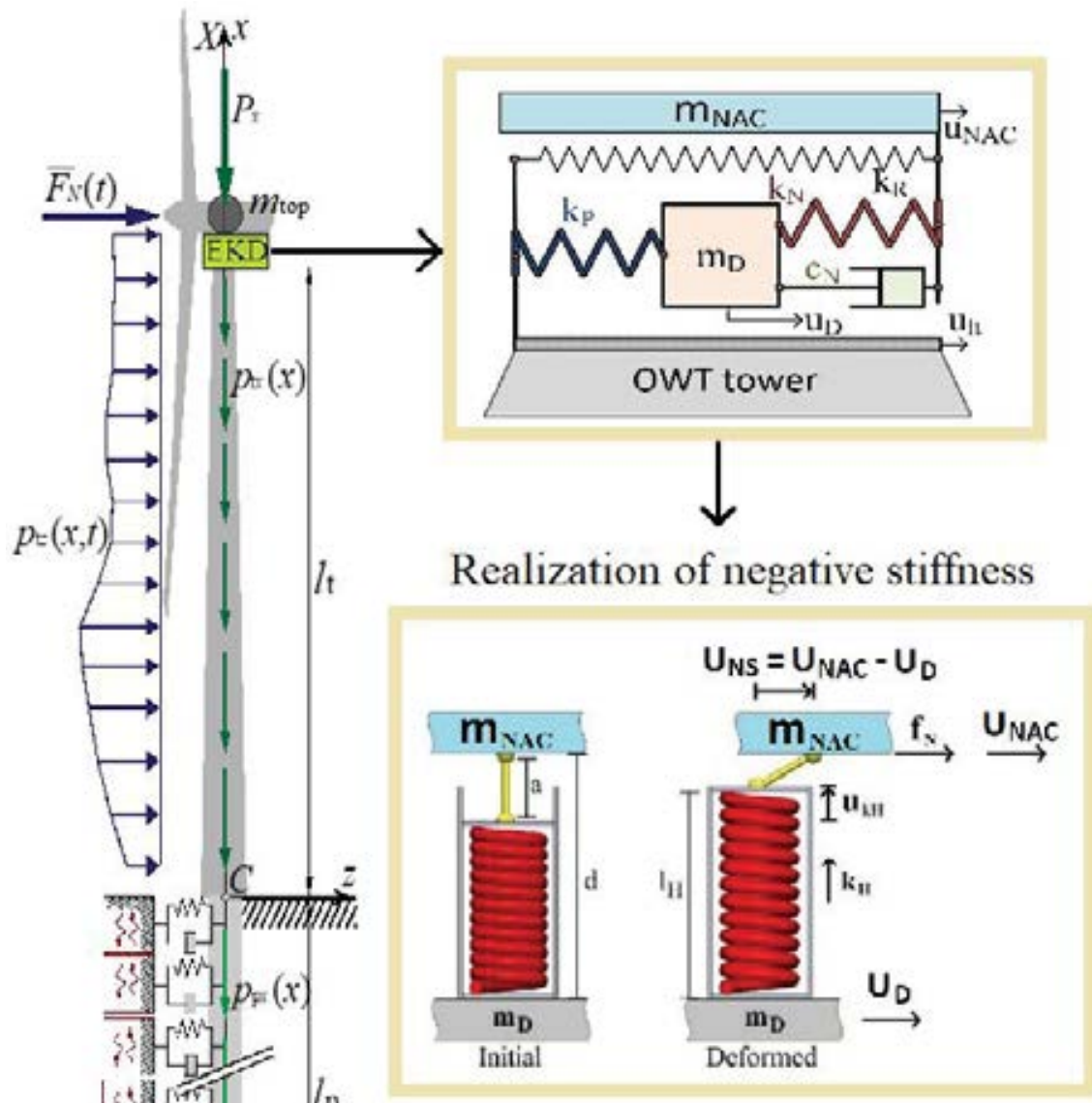

(b)

Figure 1: Wind turbine tower of variable cross section founded on monopile foundation. (a) Uncontrolled structure, and (b) controlled structure with EKD at the top of the WT tower. 
The transient nonlinear dynamic response analysis of the tower-pile system is investigated through a Beam of Variable Cross Section over a Beam on Winkler Foundation formulation accounting for both kinematic and inertia interaction. Considering large displacements and employing the second Piola-Kirchhoff stress tensor, the geometrically nonlinear equations of motion of the WT are obtained as follows:

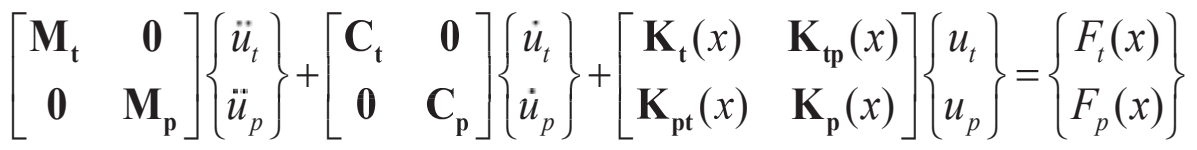

where $\left({ }^{\circ}\right)$ denotes differentiation with respect to the time $t$. Moreover, $\left[M_{t}\right],\left[M_{p}\right],\left[C_{t}\right]$ and $\left[C_{p}\right]$ are the matrices of mass and damping of the WT tower and monopile, respectively. $\left[K_{t}\right]$, $\left[K_{p}\right]$ and $\left[F_{t}\right],\left[F_{p}\right]$ are the nonlinear stiffness matrices and force vectors containing the geometrically nonlinear terms, while $\left\{u_{t}, u_{p}\right\}^{T}$ denotes the vector of unknown nodal displacements. By introducing a vibration control system (VCS) at the top of the tower, the tower related matrices of Equation 1 are modified as:

$$
\begin{aligned}
& \left.\left[\mathbf{M}_{\mathbf{t}}\right]=\left[\begin{array}{cc}
{\left[\mathbf{M}_{\mathbf{S}}\right]_{N \times N}} & {[\mathbf{0}]_{N \times n}} \\
{[\mathbf{0}]_{n \times N}} & {[\mathbf{0}]_{n \times n}}
\end{array}\right]+\left[\begin{array}{cc}
{\left[\mathbf{M}_{\mathbf{n}, \mathbf{a}}\right]_{N \times N}} & {[\mathbf{0}]_{N \times n}} \\
{[\mathbf{0}]_{n \times N}} & {\left[\mathbf{M}_{\mathbf{n}, \mathbf{d}}\right]_{n \times n}}
\end{array}\right]\right]_{(N+n) \times(N+n)} \\
& \left.\left[\mathbf{K}_{\mathbf{t}}\right]=\left[\begin{array}{cc}
{\left[\mathbf{K}_{\mathbf{S}}\right]_{N \times N}} & {[\mathbf{0}]_{N \times n}} \\
{[\mathbf{0}]_{n \times N}} & {[\mathbf{0}]_{n \times n}}
\end{array}\right]+\left[\begin{array}{cc}
{\left[\mathbf{K}_{\mathbf{n}, \mathbf{a}}\right]_{N \times N}} & -\left[\mathbf{K}_{\mathbf{n}, \mathbf{b}}\right]_{N \times n} \\
-\left[\mathbf{K}_{\mathbf{n}, \mathbf{c}}\right]_{n \times N} & {\left[K_{\mathbf{n}, \mathbf{d}}\right]_{n \times n}}
\end{array}\right]\right]_{(N+n) \times(N+n)} \\
& \left.\left[\mathbf{C}_{\mathbf{t}}\right]=\left[\begin{array}{cc}
{\left[\mathbf{C}_{\mathbf{s}}\right]_{N \times N}} & {[\mathbf{0}]_{N \times n}} \\
{[\mathbf{0}]_{n \times N}} & {[\mathbf{0}]_{n \times n}}
\end{array}\right]+\left[\begin{array}{cc}
{\left[\mathbf{C}_{\mathbf{n}, \mathbf{a}}\right]_{N \times N}} & -\left[\mathbf{C}_{\mathbf{n}, \mathbf{b}}\right]_{N \times n} \\
-\left[\mathbf{C}_{\mathbf{n}, \mathbf{c}}\right]_{n \times N} & {\left[\mathbf{C}_{\mathbf{n}, \mathbf{d}}\right]_{n \times n}}
\end{array}\right]\right]_{(N+n) \times(N+n)}
\end{aligned}
$$

where $\left[M_{N}\right]$ is the $N \times N$ mass matrix of the uncontrolled WT tower with $N$ DoF while $\left[M_{n}\right]$ indicates the $n \times n$ mass matrix of the VCS. Similarly, $\left[C_{N}\right]$ and $\left[K_{N}\right]$ are the Rayleigh damping matrix and the condensed stiffness matrix corresponding to the sway DoF. The expressions of the matrices in Equation 2 depend on the VCS of choice (TMD, EKD).

\subsection{Wind Loads}

In this paper, the aerodynamic load is taken into account by employing a basic wind velocity at the altitude of $10 \mathrm{~m}, V_{b}$ and applying the corresponding regulations of (EN 1991 Wind actions, 2010). Moreover, in order to account the wind velocity fluctuation at the altitude of $l_{\mathrm{t}}$, an artificial velocity time history is generated by applying the procedures presented in [29-32] assuming a standard deviation $\sigma$. The total concentrated force exerted on the top of the tower is computed as in [27]. Apart from the concentrated force applied on the top of the steel tower due to operation of the turbine, an additional distributed loading along the tower height is taken into account due to the fact that a portion of wind forced is exerted directly on the tower. The spatial and time distribution of this loading is obtained by employing the procedures of (EN 1991 - Wind actions, 2010) and of the studies [29-31]. The basic wind velocity that is employed has corresponding standard deviation $V_{\mathrm{b}}=27.0 \mathrm{~m} / \mathrm{s}$ with $\sigma=3.30 \mathrm{~m} / \mathrm{s}$ $\left(V_{\mathrm{m}}(120 \mathrm{~m})=39.93 \mathrm{~m} / \mathrm{s}\right)$. The rotor is assumed to develop a constant angular velocity $\Omega_{\mathrm{bl}}=$ $12.1 \mathrm{rpm}$, while all the necessary blade profile characteristics are retrieved from [26,32]. Figure 2.a presents the mean wind velocity, and Figure 2.b the time history of the evaluated total forces $\bar{F}_{N}(t)$ for the aforementioned basic wind velocity $\left(V_{\mathrm{b}}=27.0 \mathrm{~m} / \mathrm{s}, \sigma=3.30 \mathrm{~m} / \mathrm{s}\right)$. 


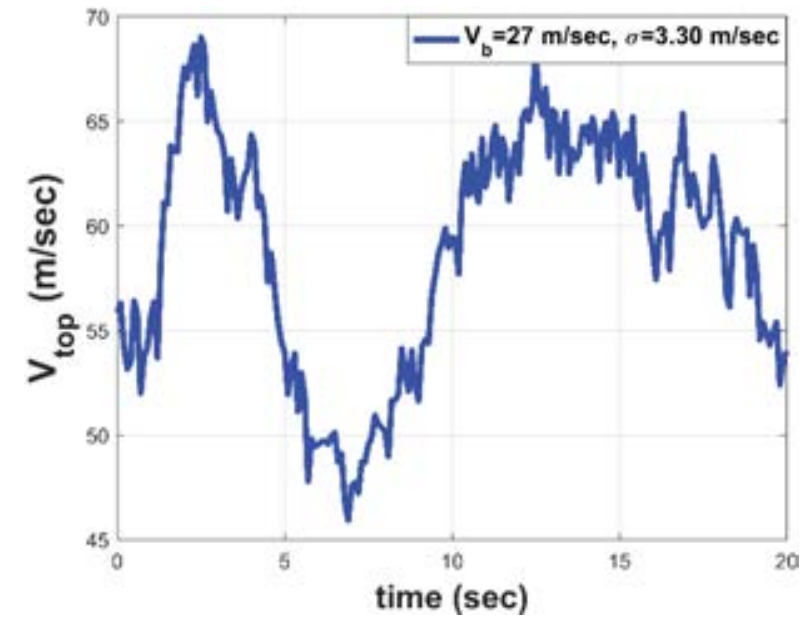

(a)

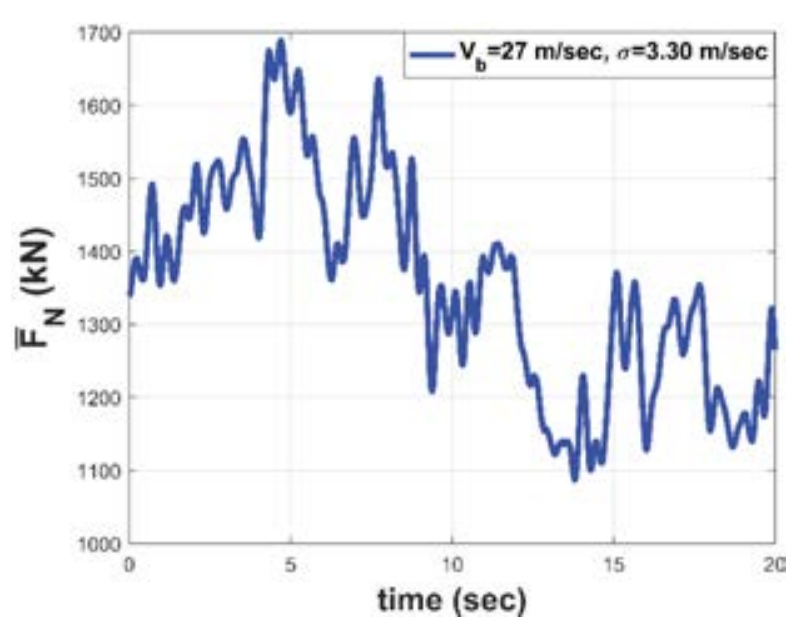

(b)

Figure 2: (a) Wind velocity at the top of the WT tower, and (b) total concentrated force exerted on the top of the WT tower $\bar{F}_{N}(t)$.

\section{IMPLEMENTATION OF VIBRATION CONTROL SYSTEMS}

\subsection{VCS Considered}

The first vibration mitigation approach is based on the classical TMD. The additional mass $\left(m_{D}\right)$ of the TMD is attached at the top of the WT tower or inside the nacelle, using a positive stiffness element and a linear damper $\left(k_{D}, c_{D}\right)$. This concept is employed as a benchmark because it has received the most attention in the literature due to the simplicity of its implementation. The main drawback of this option is the need for large additional masses, in order for the TMD to achieve significant effective damping, as will be observed in the numerical results. The parameters of the TMD configuration are presented below:

$\mu_{D}=m_{D} / m_{\text {top }}$

$\omega_{D}=2 \pi f_{D}=\sqrt{k_{D} / m_{D}}$

$\zeta_{D}=c_{D} /\left(2 \omega_{D} m_{D}\right)=c_{D} /\left(2 \sqrt{k_{D} m_{D}}\right)$

The TMD tuning frequency is selected to equal to the fundamental frequency of the primary structure $f_{D}=f_{1}$. The damping ratio affects the transferred vibrating energy to the oscillating mass of the TMD, and the TMD stroke. As the damping ratio decreases, more energy is transferred to $m_{D}$, as the oscillating mass has an increased stroke. As a result, the TMD is more effective. However, the TMD stroke is upper bounded due to the geometrical limitation that the oscillating mass is placed at the top of the tower. For this reason, the damping ratio is selected to be equal to $10 \%$ in order to be as effective as possible, and at the same time realistic. The mass of the TMD is be equal to $2 \%$, an extreme value selected only for comparison reasons.

In this paper, an extended version of KDamper [21], will be employed at the top of the WT in order to protect the WT tower from environmental vibrations (wind), as presented in Figure 1. The additional mass, $m_{t o p}$, of the nacelle, rotor and blades is no longer rigidly attached to the WT tower but is mounted on an extended KDamper device. In this concept, the additional oscillating mass of the EKD $\left(m_{D}\right)$ is connected with the nacelle with a negative stiffness element and a linear damper $\left(k_{N S}, c_{N S}\right)$, and with the steel tower with a positive stiffness element $\left(k_{P S}\right)$, and the steel tower is connected with the nacelle with a positive stiffness connection $\left(k_{R}\right)$. This way, the EKD aims to isolate the vibrations of the nacelle form the steel tower. In 
addition, the EKD aims to increase the effective damping of the WT tower compared to the TMD with the same additional mass, as it has been proven that the KDamper always presents an improved dynamic behavior as compared to the TMD.

The configuration of the extended KDamper (EKD) implemented at the top of the WT tower is illustrated in Figure 1. The positions regarding the EKD are presented below:

$$
\begin{aligned}
& \mu_{D}=m_{D} / m_{t o p} \\
& k_{D}=k_{N S}+k_{P S} \\
& \omega_{D}=2 \pi f_{D}=\sqrt{k_{D} / m_{D}}=\sqrt{\frac{k_{N S}+k_{P S}}{m_{D}}} \\
& k_{0}=k_{R}+\frac{k_{N S} k_{P S}}{k_{N S}+k_{P S}} \\
& \omega_{0}=2 \pi f_{0}=\sqrt{k_{0} /\left(m_{D}+m_{t o p}\right)}=\sqrt{\left(k_{R}+\frac{k_{N S} k_{P S}}{k_{N S}+k_{P S}}\right) /\left(m_{D}+m_{t o p}\right)} \\
& \zeta_{N S}=c_{N S} /\left(2 m_{D} \omega_{D}\right)=c_{N S} /\left(2 \sqrt{k_{D} m_{D}}\right)
\end{aligned}
$$

where $\mu_{D}$ is the EKD additional mass ratio. In order for the proposed configuration to be realistic, the design of the EKD concept foresees variation in all the stiffness elements to ensure that the system remain statically and dynamically stable:

$\left(1-\varepsilon_{R}\right) k_{R}+\frac{\left(1-\varepsilon_{P S}\right) k_{P S}\left(1+\varepsilon_{N S}\right) k_{N S}}{\left(1-\varepsilon_{P S}\right) k_{P S}+\left(1+\varepsilon_{N S}\right) k_{N S}}=0$

Assuming that the $m_{D}$, and the values of the stability factors $\varepsilon_{N S}, \varepsilon_{P S}$, and $\varepsilon_{R}$ are supposed known, the stiffness elements $k_{P S}$ and $k_{R}$, result from Equations (4.e, 5) as a function of $f_{0}$, and $k_{N S}$. Therefore, the independent design variables sought in the optimization are:

1. the nominal frequency $f_{0}$;

2. the value of the negative stiffness (NS) element $k_{N S}$;

3. the value of the damping coefficient $c_{N S}$ );

For the optimization process, the Harmony Search (HS) algorithm, a novel metaheuristic algorithm is used [33].

\subsection{Optimal Design of EKD}

Having established the nonlinear equations of motion Equation 1 for the controlled WT, the next objective is to determine the optimal EKD parameters in order to attain the best possible vibration control strategy. The objective function and the constraints are selected from the geometrically non-linear time domain responses, are described below:

i. Assign values to the known parameters (initial guess).

a) EKD is implemented at the top of the WT tower, and as a result the additional oscillating mass is desired to be the minimum possible. Thus, $m_{D}$ varies in the range [ 0.10 .5$] \%$, one order of magnitude lower as compared to that of the TMD.

b) The stability factors of the $k_{P S}, k_{R}$ are conservatively selected as $5 \%$. The variation of the NS element $k_{N S}$, is selected equal to $10 \%$, as indicated in [21]. 
ii. Set the objective function (OF) as the minimization of the relative displacement of the WT tower. (obtained from geometrically nonlinear dynamic analysis)

$$
\min : u_{t o p}^{\operatorname{Re} l}=u_{l_{t}}-u_{l=0} \quad \text { (OF) }
$$

iii. Set the geometrical constraint regarding the relative displacement of the oscillating mass of the EKD and the top of the WT tower. The upper limit is equal to half of the top tower diameter.

$$
u_{D}^{\operatorname{Re} l}=u_{D}-u_{l_{t}} \leq D_{\text {top }} / 2 \quad \text { (Constraint 1) }
$$

iv. To ensure the effective operation of the WT. another geometrical limitation regarding the relative displacement of the nacelle and the top of the WT tower is set:

$$
u_{\text {Nac }}^{\mathrm{Re} l}=u_{n a c}-u_{l_{t}} \leq 0.5 \mathrm{~m} \quad \text { (Constraint 2) }
$$

v. Set an upper limit for the damping coefficients $c_{N S}$ with respect to the superstructure mass. This constraint is based on previous works [47] as well as on manufacturing restrictions:

$$
c_{N S} \leq 1000 \mathrm{kNS} / \mathrm{m} \quad \text { (Constraint 3) }
$$

vi. Set an upper limit for the NS per $1 \mathrm{tn}$ of structure mass [14]:

$$
k_{N S} \geq-50 \mathrm{kN} / \mathrm{m} \quad \text { (Constraint 4) }
$$

vii. The nominal frequency $f_{0}$ of the SBA varies in the range [0.1 5] Hz, (Constraint 5).

Finally, the limits of the free design variables are: a) nominal frequency $\left.f_{0}(\mathrm{~Hz})[0.15 .0], \mathrm{b}\right)$ value of the NS element $k_{N S}(\mathrm{kN} / \mathrm{m})$ [-20000 - 1 , and c) damping coefficient $c_{N S}(\mathrm{kNs} / \mathrm{m})$ [ 1 1000]. As for the parameters inherently involved in the HS algorithm, the commonly used values in relative literature are employed: $\mathrm{HMS}=75, \mathrm{HMCR}=0.5$, and $\mathrm{PAR}=0.1$.

\section{NUMERICAL APPLICATION}

\subsection{Considered WT tower and monopile systems}

In this section, the NREL baseline 5-MW nacelle and rotor, supported by a steel tower of $120 \mathrm{~m}$ height is examined. This choice is made due to the fact that is widely used in the literature as a benchmark option for vibration control of WT towers. The key properties of the wind turbine and the steel tower are listed in Table 1 and Table 2 respectively.

As far as monopile system is concerned, a steel tubular pile of constant cross section $\left(E_{p}=2.1 \times 10^{8} \mathrm{kN} / \mathrm{m}^{2}, \rho_{p}=7.8 \mathrm{th} / \mathrm{m}^{3}, v_{p}=0.3, G_{p}=8.0769 \times 10^{7} \mathrm{kN} / \mathrm{m}^{2}, l_{p}=30.0 \mathrm{~m}, D_{p}=5.0 \mathrm{~m}\right.$, $\left.t_{p}=0.08 \mathrm{~m}\right)$ is considered. The undrained shear strength of the soil profile is assumed to follow a parabolic distribution with depth with mean $S_{u}=60 \mathrm{kPa}$, mass density $\gamma=1 \mathrm{tn} / \mathrm{m}^{3}$ and modulus of elasticity $E=1800 S_{u}$. The whole structure is subjected to the action of its total weight (including mechanical parts). More specifically, a distributed axial load along the length of the structure and a concentrated axial force at its top are applied, which are evaluated according to the corresponding masses. 


\begin{tabular}{c|c}
\hline Property & Value \\
\hline Rating & $5 \mathrm{MW}$ \\
Rotor diameter & $126 \mathrm{~m}$ \\
Hub diameter & $3 \mathrm{~m}$ \\
Cut-in wind speed & $3 \mathrm{~m} / \mathrm{sec}$ \\
Rated wind speed & $11.4 \mathrm{~m} / \mathrm{sec}$ \\
Cut-out wind speed & $25 \mathrm{~m} / \mathrm{sec}$ \\
Cut-in rotor speed & $6.9 \mathrm{rpm}$ \\
Rated rotor speed & $12.1 \mathrm{rpm}$ \\
Nacelle mass & $240,000 \mathrm{~kg}$ \\
Rotor mass & $110,000 \mathrm{~kg}$ \\
Blade material & Glass-fibre \\
Blade length & $61.5 \mathrm{~m}$ \\
Blade mass & $17,740 \mathrm{~kg}$ \\
Blade CM (from blade root) & $20.475 \mathrm{~m}$ \\
Blade damping ratio (all modes) & $0.48 \%$ \\
\hline
\end{tabular}

Table 1: Key properties of NREL baseline $5 \mathrm{MW}$ wind turbine.

\begin{tabular}{c|c}
\hline Property & Value \\
\hline Height & $120 \mathrm{~m}$ \\
Base diameter & $8.43 \mathrm{~m}$ \\
Base steel thickness & $0.048 \mathrm{~m}$ \\
Top diameter & $3.87 \mathrm{~m}$ \\
Top steel thickness & $0.025 \mathrm{~m}$ \\
Young's modulus & $210 \mathrm{GPa}$ \\
Steel density & $8,500 \mathrm{~kg} / \mathrm{m}^{3}$ \\
Total mass & $798,640 \mathrm{~kg}$ \\
Location of CM (above base) & $43.042 \mathrm{~m}$ \\
Tower damping ratio (all modes) & $1 \%$ \\
\hline
\end{tabular}

Table 2: Key properties of the considered steel tower.

\subsection{Nonlinear dynamic model verification}

In order to verify the validity and the efficiency of the developed formulation, a set of simplified analyses were conducted and the obtained results were compared with those obtained from the commercial software package SOFiSTiK [34] based on FEM. More specifically, in Table 3, the first 5 eigenperiods of vibration, are presented using SOFiSTiK, and are com- 
pared with those obtained from a FEM solution employing 24 prismatic beam elements for the tower and 60 for the monopile. Furthermore, the response of each tower configuration is examined performing a simplified linear static analysis, applying a concentrated force at the top of the tower. Table 3 presents the static deflections $X_{\text {top }}$ at the top of the WT tower obtained from the developed model of the WT tower as compared with the aforementioned FEM solution, using SOFiSTiK software. It can be observed that the validity of the developed model of the WT tower is verified, as both the values of the WT eigenperiods and the static deflection of the top of the WT tower are in a very good agreement.

\begin{tabular}{c|c|c|c|c|c|c}
\hline & \multicolumn{5}{|c|}{ Eigenperiods $(\mathrm{sec})$} & $\begin{array}{c}\text { Static deflection at the top } \\
\text { of the tower } X_{\text {top }}(\mathrm{m})\end{array}$ \\
\cline { 2 - 7 } & $\mathrm{T} 1$ & $\mathrm{~T} 2$ & $\mathrm{~T} 3$ & $\mathrm{~T} 4$ & $\mathrm{~T} 5$ & 1.225 \\
\hline Present Study & 4.315 & 0.727 & 0.243 & 0.122 & 0.076 & 1.233 \\
\hline SOFiSTiK & 4.310 & 0.726 & 0.246 & 0.128 & 0.081 & \\
\hline
\end{tabular}

Table 3: Eigenperiods of the WT tower, and static deflection at the top of the tower under static analysis.

\subsection{Dynamic responses}

The design parameters selected for the TMD system are $\mu_{D}=2 \%, \zeta_{D}=10 \%$, and $f_{D}=f_{1}$, where $f_{1}$ is the fundamental frequency of the primary structure. Regarding the EKD system, the selected additional mass is equal to $\mu_{D}=0.1 \%, 20$ times lower as compared to that of the TMD, and the stability factors $\varepsilon_{N S}, \varepsilon_{P S}$, and $\varepsilon_{R}$ are selected as $10 \%, 5 \%$, and $5 \%$, respectively. The optimal EKD parameters obtained following the procedure presented in Section 3.2, are presented in Table 4.

\begin{tabular}{c|c|c|c|c|c|c}
\hline \multicolumn{2}{c|}{ Fixed values } & \multicolumn{3}{c|}{ Independent design variables } & \multicolumn{2}{c}{ Resulting stiffnesses } \\
\hline$m_{D}(t n)$ & $\varepsilon_{N S}, \varepsilon_{P S}, \varepsilon_{R}(\%)$ & $f_{0}(\mathrm{~Hz})$ & $k_{N S}(\mathrm{kN} / \mathrm{m})$ & $c_{N S}(\mathrm{kN} / \mathrm{m})$ & $k_{R}(\mathrm{kN} / \mathrm{m})$ & $k_{P S}(\mathrm{kN} / \mathrm{m})$ \\
\hline 0.403 & $10,5,5$ & 0.3664 & -9089.7 & 511.69 & 13057 & 54275 \\
\hline
\end{tabular}

Table 4: Optimal EKD parameters.

The dynamic response of the WT tower relative displacement is presented in Figure 3.a, for the uncontrolled WT, as well as the controlled WT with a conventional TMD (2\%), and the proposed EKD $(0.1 \%)$ implemented at the top of the WT. It is observed that due to the nature of the external load, the first peak of the dynamic response is not affected by either system, however, the $2^{\text {nd }}$ peak is greatly reduced with the EKD system. As a result, the effective damping of the controlled system is significantly increased. In order to calculate the exact value of the effective damping, the initial and the controlled structures are subjected to a free vibration with initial conditions, as illustrated in Figure 4, and more specifically to that of the first modal eigenform of the uncontrolled structure. The effective damping is then calculated with the following logarithmic rule:

$$
\ln \left[\frac{u_{t o p}^{\mathrm{Re} l}(t)}{u_{t o p}^{\mathrm{Re} l}(t+T)}\right]=\frac{2 \pi \zeta_{\text {eff }}}{\sqrt{1-\zeta_{\text {eff }}^{2}}}
$$

where $T$ is the time between two consecutive peaks of the dynamic response, and $u_{\text {top }}{ }^{R e l}$ is the top tower relative displacement. The effective damping of the initial structure, the TMD and the EKD systems are $2.67 \%, 2.98 \%$, and $8.36 \%$. The TMD system slightly increases the effective damping, while the EKD system has more than 3 times the initial effective damping. 


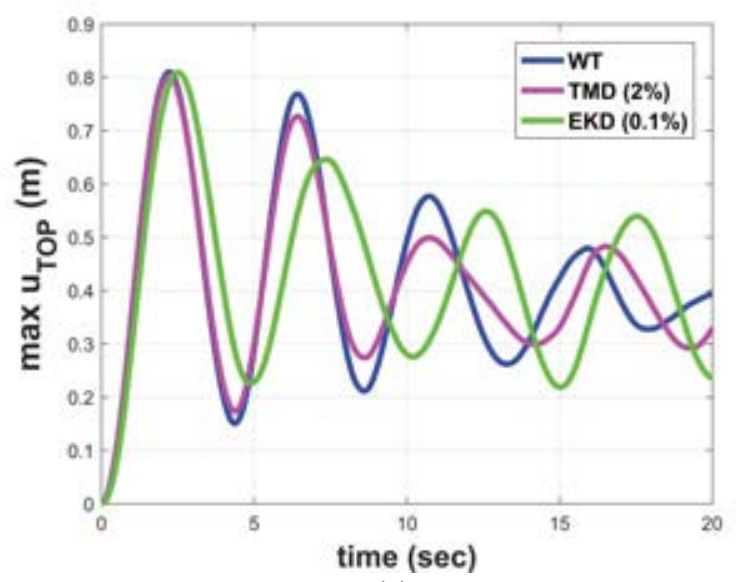

(a)

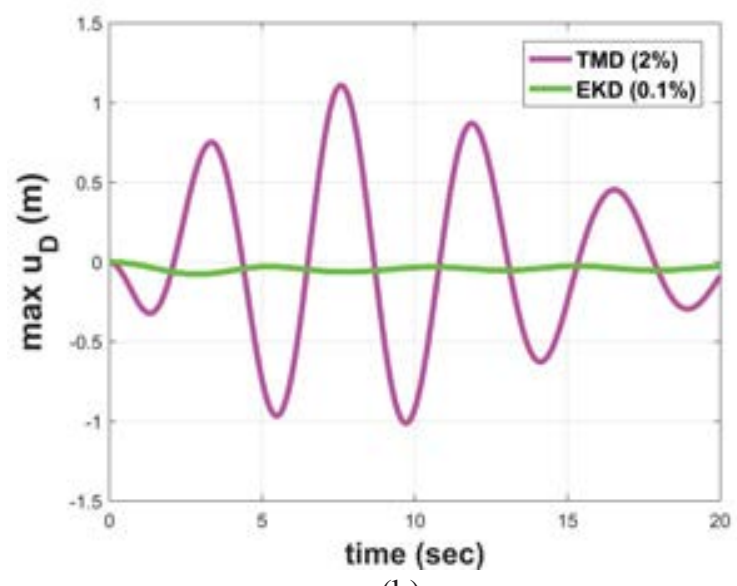

(b)

Figure 3: (a) Dynamic response of the WT tower top relative displacement of the initial, the TMD and the EKD systems. (b) Additional oscillating mass relative to the tower displacement of the TMD and EKD systems.

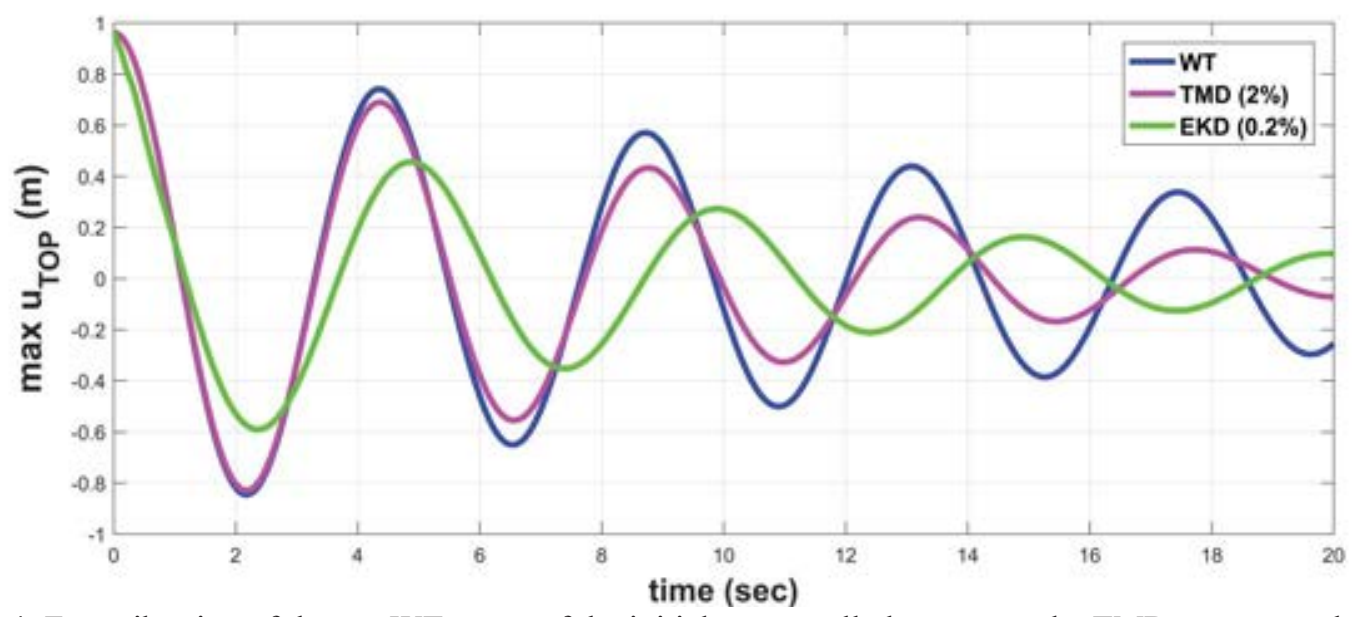

Figure 4: Free vibration of the top WT tower of the initial uncontrolled structure, the TMD system, and the EKD.

The initial displacement conditions imposed are according to the first modal eigenform of the initial WT.

Finally, the relative displacement of the additional oscillating mass of the TMD and EKD systems, is presented in Figure 3.b. The additional mass of the EKD has a stroke more than one order of magnitude smaller, as compared to that of the TMD. More specifically, the peak of the additional mass stroke is $1.11 \mathrm{~m}$ with the TMD system, and $0.076 \mathrm{~m}$ with the EKD system.

\section{CONCLUSIONS}

In this paper, a novel passive vibration absorption and damping concept, the extended KDamper, is examined for improving the WT tower dynamic behavior and increasing the effective damping. A wind turbine of 5MW supported by a steel tower of $120 \mathrm{~m}$ founded on a monopile was analyzed under a horizontal aerodynamic load due to the wind. The developed nonlinear dynamic model is an assemblage of prismatic beam elements, the validity of which is verified based on a comparison with a commercial software package on FEM. The aerodynamic load is taken into account by generating artificial basic wind velocities applying the corresponding regulations of EC1, Part1,4. The proposed vibration control system (VCS) is designed based on a constrained optimization procedure, that accounts for geometrical, con- 
structional and manufacturing limitations. Based on the performed nonlinear dynamic analysis, the following conclusive remarks can be made:

i. The proposed nonlinear dynamic model is effective and efficient in implementing VCS for vibration control of WT.

ii. The employed additional mass is significantly lower $(0.1 \%, 0.403 \mathrm{tn})$ as compared to a conventional TMD $(2 \%, 8.6 \mathrm{tn})$.

iii. The EKD increases the effective damping (8.36\%) of the WT tower more than 3 times compared to the initial WT $(2.67 \%)$, while the TMD system achieves only a slight increase $(2.98 \%)$.

iv. The additional mass stroke in the EKD is in the order of a few centimeters $(7.6 \mathrm{~cm})$, overcoming the fundamental disadvantage of the TMD that requires large strokes, more than $1 \mathrm{~m}$.

\section{ACKNOWLEDGMENTS}

This research has been co-financed by the European Union and Greek national funds through the Operational Program Competitiveness, Entrepreneurship and Innovation, under the call RESEARCH - CREATE - INNOVATE (project code: T1EDK-02827).
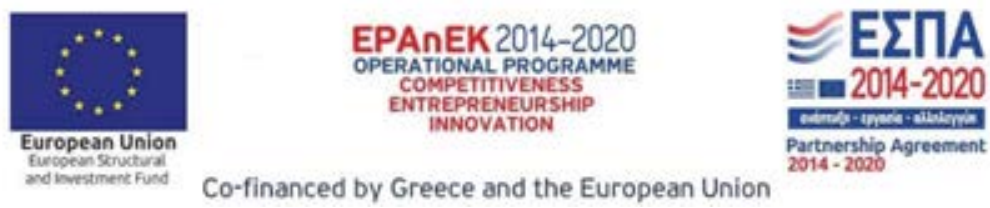

\section{REFERENCES}

[1] Li, Y., 2018, "Research and Development of the Wind Turbine Reliability," Int. J. Mech. Eng. Appl., 6(2), p. 35.

[2] "Sustainable Development Scenario - World Energy Model - Analysis - IEA" [Online]. Available: https://www.iea.org/reports/world-energy-model/sustainable-developmentscenario. [Accessed: 24-Apr-2020].

[3] Frahm, H., 1911, "Device for Damping of Bodies," U.S. Pat., (989).

[4] Soong, T. T., and Dargush, G. F., 1997, Passive Energy Dissipation Systems in Structural Engineering, Wiley.

[5] Casciati, F., and Giuliano, F., 2009, "Performance of Multi-TMD in the Towers of Suspension Bridges,” J. Vib. Control, 15(6), pp. 821-847.

[6] Ricciardelli, F., Pizzimenti, A. D., and Mattei, M., 2003, "Passive and Active Mass Damper Control of the Response of Tall Buildings to Wind Gustiness," Eng. Struct., 25(9), pp. 1199-1209.

[7] Ankireddi, S., and Yang, H. T. Y., 1996, "Simple ATMD Control Methodology for Tall Buildings Subject to Wind Loads," J. Struct. Eng., 122(1), pp. 83-91.

[8] Liao, G. J., Gong, X. L., Kang, C. J., and Xuan, S. H., 2011, "The Design of an Active-Adaptive Tuned Vibration Absorber Based on Magnetorheological Elastomer and Its Vibration Attenuation Performance," Smart Mater. Struct., 20(7), p. 075015.

[9] Weber, F., Boston, C., and Maślanka, M., 2011, "An Adaptive Tuned Mass Damper Based on the Emulation of Positive and Negative Stiffness with an MR Damper," Smart Mater. Struct., 20(1), p. 015012.

[10] Casciati, F., Rodellar, J., and Yildirim, U., 2012, "Active and Semi-Active Control of 
Structures - Theory and Applications: A Review of Recent Advances," J. Intell. Mater. Syst. Struct., 23(11), pp. 1181-1195.

[11] Acar, M. A., and Yilmaz, C., 2013, "Design of an Adaptive-Passive Dynamic Vibration Absorber Composed of a String-Mass System Equipped with Negative Stiffness Tension Adjusting Mechanism," J. Sound Vib., 332(2), pp. 231-245.

[12] Weber, F., 2014, "Optimal Semi-Active Vibration Absorber for Harmonic Excitation Based on Controlled Semi-Active Damper,” Smart Mater. Struct., 23(9), p. 095033.

[13] Weber, B., and Feltrin, G., 2010, “Assessment of Long-Term Behavior of Tuned Mass Dampers by System Identification,” Eng. Struct., 32(11), pp. 3670-3682.

[14] Antoniadis, I. A., Kanarachos, S. A., Gryllias, K., and Sapountzakis, I. E., 2018, "KDamping: A Stiffness Based Vibration Absorption Concept," JVC/Journal Vib. Control, 24(3), pp. 588-606.

[15] Kapasakalis, K., Sapountzakis, E., and Antoniadis, I., 2017, "Implementation of the KDamper Concept to Wind Turbine Towers," Proceedings of the 6th International Conference on Computational Methods in Structural Dynamics and Earthquake Engineering (COMPDYN 2017).

[16] Kapasakalis, K., Antoniadis, I., and Sapountzakis, E., 2019, "Control of Multi Storey Building Structures with a New Passive Vibration Control System Com-Bining Base Isolation with KDamper," Proceedings of the 7th International Conference on Computational Methods in Structural Dynamics and Earthquake Engineering (COMPDYN 2019).

[17] Antoniadis, I., Kapasakalis, K., and Sapountzakis, E., 2019, "Advanced Negative Stiffness Absorbers for the Seismic Protection of Structures," Proceedings of the International Conference on Key Enabling Technologies 2019 (KEYTECH2019).

[18] Kapasakalis, K., Antoniadis, I., and Sapountzakis, E., 2019, "Performance Assessment of the KDamper as a Seismic Absorption Base," Struct. Control Heal. Monit.

[19] Kapasakalis, K., Antoniadis, I., and Sapountzakis, E., 2019, "KDamper Concept for Base Isolation and Damping of High-Rise Building Structures," Proceedings of the 14th International Conference on Vibration Problems (ICOVP 2019).

[20] Kapasakalis, K., Sapountzakis, E., and Antoniadis, I., 2018, "Optimal Design of the KDamper Concept for Structures on Compliant Supports," Proceedings of the 16th European Conference on Earthquake Engineering (16ECEE 2018).

[21] Kapasakalis, K. A., Antoniadis, I. A., and Sapountzakis, E. J., 2021, "Constrained Optimal Design of Seismic Base Absorbers Based on an Extended KDamper Concept," Eng. Struct., 226.

[22] Kapasakalis, K. A., Alvertos, A. E., Mantakas, A. G., Antoniadis, I. A., and Sapountzakis, E. J., 2020, “Advanced Negative Stiffness Vibration Absorber Coupled with Soil-Structure Interaction for Seismic Protection of Buildings," Proceedings of the International Conference on Structural Dynamic , EURODYN, European Association for Structural Dynamics, pp. 4160-4176.

[23] Kapasakalis, K. A., Bollano, P. O. N., Sapountzakis, E. J., and Antoniadis, I. A., 2020, "Comparison of Alternative Dynamic Vibration Mitigation Approaches for Wind Turbine Towers," Proceedings of the International Conference on Structural Dynamic , EURODYN, European Association for Structural Dynamics, pp. 1358-1372.

[24] Kapasakalis, K. A., Antoniadis, I. A., and Sapountzakis, E. J., 2020, "Optimal Design of Advanced Negative Stiffness Absorbers," Proceedings of the International Conference on Structural Dynamic , EURODYN, European Association for Structural Dynamics, pp. 4177-4188.

[25] Hansen, M. O. L., 2008, Aerodynamics of Wind Turbines, Earthscan. 
[26] Quilligan, A., O’Connor, A., and Pakrashi, V., 2012, "Fragility Analysis of Steel and Concrete Wind Turbine Towers," Eng. Struct., 36, pp. 270-282.

[27] Sapountzakis, E. J., Dikaros, I. C., Kampitsis, A. E., and Koroneou, A. D., 2015, "Nonlinear Response of Wind Turbines under Wind and Seismic Excitations with SoilStructure Interaction," J. Comput. Nonlinear Dyn., 10(4).

[28] 2010, EN 1991-1-4: Eurocode 1: Actions on Structures - Part 1-4: General Actions Wind Actions.

[29] Koulatsou, K., Petrini, F., Vernardos, S., and Gantes, C. J., 2013, Artificial Time Histories of Wind ActionsFor Structural Analysis of Wind Turbines.

[30] M, D. P., 1998, "Digital Simulation of Wind Field Velocity," J. Winf Eng. Ind. Aerodyn., (74-76), pp. 91-109.

[31] Norske Veritas (Organization), and Forskningscenter Risø., 2002, Guidelines for Design of Wind Turbines., Det Norske Veritas, Copenhagen ;[Roskilde Denmark].

[32] Jonkman, J. M., 2007, Dynamics Modeling and Loads Analysis of an Offshore Floating Wind Turbine. Technical Report No. NREL/TP-500-41958.

[33] Zong Woo Geem, Joong Hoon Kim, and Loganathan, G. V., 2001, "A New Heuristic Optimization Algorithm: Harmony Search,” Simulation, 76(2), pp. 60-68.

[34] "FEM, BIM and CAD Software for Structural Engineers | SOFiSTiK AG” [Online]. Available:

https://www.sofistik.com/? hstc=136929903.778d8a8e3515c0a0f7da049d7f27258a. 1 $587748377743.158774837 \overline{77} 43.1587748377743 .1 \& \_\mathrm{hssc}=136929903.2 .1587748377$ 744\&_hsfp=4014916924. [Accessed: 24-Apr-2020]. 